\title{
RESISTIVITY SURVEYS EMPLOYED TO STUDY COASTAL AQUIFERS IN THE STATE OF BAHIA, BRAZIL
}

\author{
J.L. LEITE and R.D. BARKER
}

Programa de Pesquisa e Posgraduação em Geofísica, Universidade Federal da Bahia, Salva. dor (Brazil)

Department of Geological Sciences, University of Birmingham, Birmingham (Great Britain) (Received May 12, 1977; accepted January 12, 1978)

\begin{abstract}
Leite, J.L. and Barker, R.D., 1978. Resistivity surveys employed to study coastal aquifers in the state of Bahia, Brazil. Geoexploration, 16: 251-257.

Resistivity sounding surveys are currently employed by members of the Programa de Pesquisa e Posgraduação em Geofísica at the Federal University of Bahia, Brazil, in the study of groundwater problems. The tripotential technique with the Wenner configuration is preferred to other more traditional methods. Higher quality and more useful results are obtained. An example from the city of Canavieiras, Bahia, Brazil, is detailed.
\end{abstract}

\section{INTRODUCTION}

In general, the tropical coast of Brazil receives a very high rainfall and potential water supplies abound. In such a climate, the possibility that surface supplies would become contaminated by disease is very high and for this reason it is the groundwater resources that are generally exploited for public supply to the small coastal towns. In recent years the small town populations have grown and the subsequent demand for more water is being met by the drilling of boreholes by the State Water Authority, C.E.R.B.

The water is normally drawn from the alluvial sands which form a broken strip, often more than $10 \mathrm{~km}$ wide, bordering the northeastern coast of Brazil. These sands are highly porous and yield high quality water. In some places, however, unexpected, high-salinity groundwaters have been encountered.

As part of the exploration of these coastal aquifers and the study of the problems of their exploitation, a programme of electrical resistivity surveys has been initiated by the members of the Programa de Pesquisa e Posgraduacão em Geofísica, at the Federal University of Bahia, Brazil (Leite, 1975). The methods employed are discussed and an example from the city of Canavieiras is detailed. 


\section{FIELD SURVFY PROCEDURES}

Although the water table along the coast of Brazil is normally within $2 \mathrm{~m}$ of the surface, the soil is often dry and contains little or no carbonaceous material. High contact resistances between the electrodes and the sand result in too little current entering the ground and the consequent malfunction of the instrument - an ABEM AC Terrameter.

To identify electrode contact problems and also those of instrument malfunction due to damaged cables, the tripotential technique of resistance measurement was adopted together with the Wenner electrode configuration. The tripotential method, in a general form, was first described by Wenner (1912) but the following nomenclature is due to Carpenter (1955).

With a configuration of four collinear point electrodes, it is possible to obtain three distinct arrangements of potential $(\mathrm{P})$ and current $(\mathrm{C})$ electrodes. These are termed the $\alpha, \beta$ and $\gamma$ electrode arrangements and are those in which the electrodes are placed in the orders CPPC, CCPP and CPCP, respectively. The resistances measured with each arrangement are referred to as $R_{\alpha}, R_{\beta}$ and $R \gamma$

It can be shown (Wenner, 1912) that:

$R_{\alpha}=R_{\beta}+R_{\gamma}$

This equation has an important field application especially where dry sandy soils produce high contact resistances at the electrodes. By comparing $R_{\alpha}$ with the sum of $R_{\beta}$ and $R_{\gamma}$, errors due to instrument malfunction (i.e., current leakage from damaged cables, high contact resistances etc.) can be rapidly detected. In the absence of instrument problems equation (1) will be satisfied under any geological conditions and for any electrode arrangement.

Although, theoretically the tripotential technique may be applied with any electrode configuration, in practice it is of use only where $R_{\alpha}, R_{\beta}$ and $R_{\gamma}$ are of the same order of magnitude. Such characteristics are not those of the Schlumberger configuration but are, however, furnished by the Wenner configuration.

The tripotential field test was also preferred to the simpler test for reciprocity for in the former, additional information is obtained which may often indicate the influence of subsurface lateral resistivity variations on the observed apparent resistivity curve. The reciprocal test has only a field application and does not provide further information.

\section{DATA PROCESSING AND INTERPRETATION}

The error in the tripotential relationship given by:

$e=\frac{R_{\alpha}-\left(R_{\gamma}+R_{\beta}\right)}{R_{\alpha}+R_{\beta}+R_{\gamma}} \cdot 100 \%$

is normally less than $2 \%$ although up to $5 \%$ may be tolerated as acceptable ob- 
servational crror. This error can be distributed between the three resistances before calculation and construction of the apparent resistivity curves.

A measure of the effect of lateral resistivity variations on the observed curve can be obtained from the calculation, at each spacing, $s$, of a parameter, $C(s)$, obtained from the following equation (Carpenter and Habberjam, 1956):

$C(s)-\left\{4 \rho_{\alpha}(s)+\rho_{\gamma}(3 s)\right\} /\left\{3 \rho_{\alpha}(s)+2 \rho_{\gamma}(2 s)\right\}$

where $\rho_{\alpha}(s)$ is the apparent resistivity measured with spacing, $s$, using the $\alpha$ electrode arrangement.

With purely horizontally-layered conditions, $C(s)$ will always be equal to unity. Any departures from this value will indicate the presence of lateral resistivity variations. Such departures are considered significant if they lie outside the range $0.75-1.25$ and in these cases the apparent resistivity curves are visually smoothed.

It is important to note that the converse argument does not hold and that a value for $C(s)$ of unity does not necessarily mean the absence of lateral resistivity variations. For this reason the $\alpha, \beta$ and $\gamma$ apparent resistivity curves are examined together. For a horizontally layered medium all three curves should have the same general form and should, of course, give the same result on interpretation. Soundings which show a large disparity between the three curves should be treated with caution.

The interpretation of the smoothed sounding curves followed the scheme presented in Fig. 1 (system $a$ ). The observed apparent resistivity curves were interpreted using standard partial curve matching techniques and then converted to the resistivity transform using the technique of Ghosh (1971). The theoretical transform obtained from the interpretation model could then be calculated and compared with the observed transform thus providing a control on the interpretation. The adjustment could be repeated in an iterative

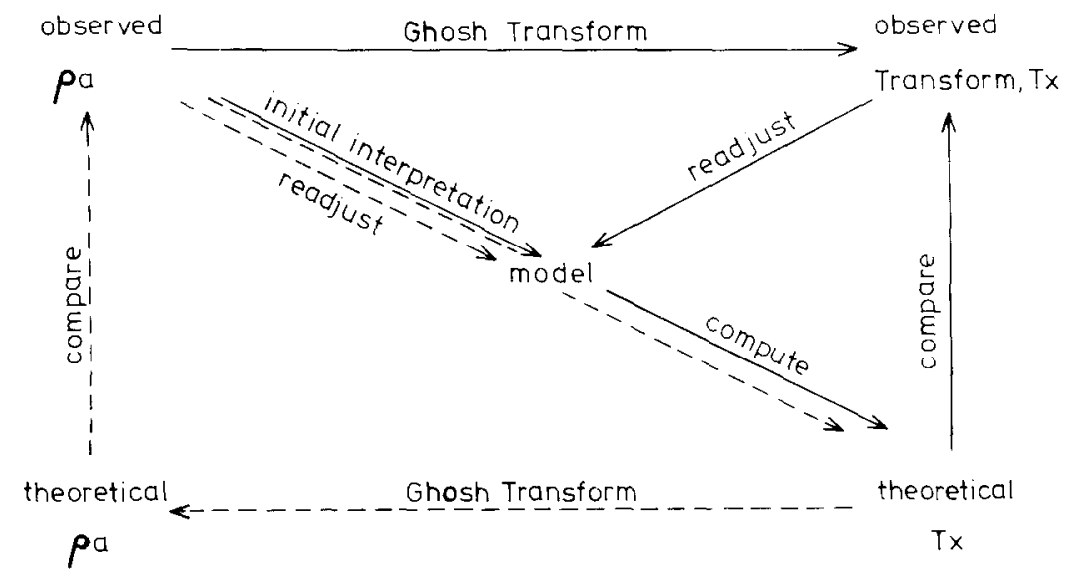

Fig. 1. Interpretation of resistivity sounding curves: solid lines $=$ system $a$, broken lines $=$ system $b$. 
way until the generated curve agreed closely with the observed curve. This technique was chosen so that the whole interpretation could be rapidly conducted in the field of fice on a table calculator with limited memory.

System $b$ (Fig. 1) has the advantage that the interpretation is conducted throughout using apparent resistivity curves. Because an additional transform is involved which is repeated in each adjustment, this system depends for speed on access to a small computer. In system $a$, the transform is eliminated from the iterative adjustment process and the computations are thus greatly reduced. In this way a whole range of equivalent models could be tested by rapid calculation of their transforms and comparison with the observed transform.

\section{A RESISTIVITY SURVEY AROUND CANA VIEIRAS, BRAZIL}

Canavieiras is a town typical of the tropical coast of Brazil. Its water is sup. plied from wells drilled into Quarternary sands, gravels and clays which overlie Tertiary sandstones (Fig. 2). These sandstones outcrop about $10 \mathrm{~km}$ to the west from whence they dip eastwards under the coastal strip of recent alluvium.

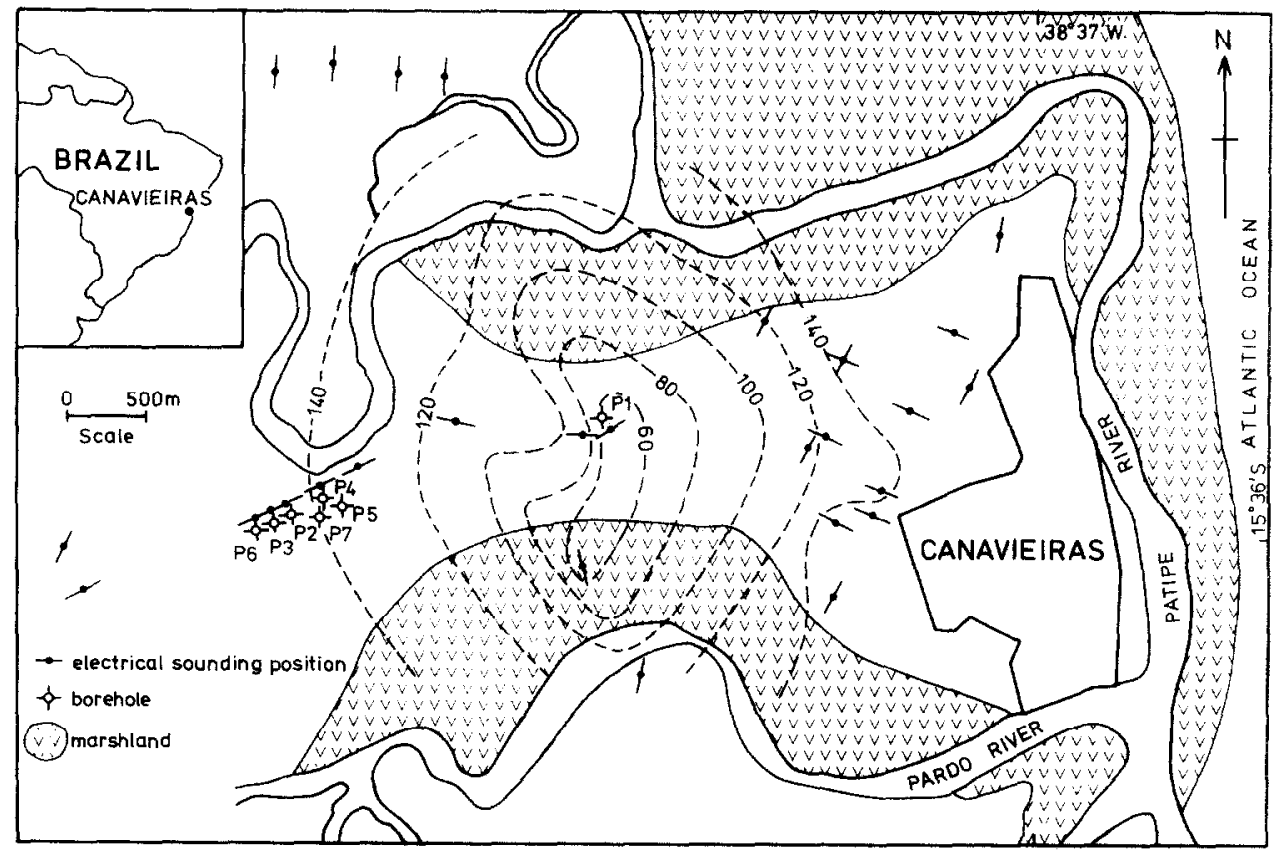

Fig. 2. Area around Canavieiras, Brazil, showing electrical sounding positions and boreholes. Contours represent lines of equal resistivity of aquiferous sands in $52 \mathrm{~m}$. 
Most of the wells (P2-P7) were sunk in a group $4 \mathrm{~km}$ to the west of the town where potable water with approximately $130 \mathrm{mg} \mathrm{I}^{-1}$ of total dissolved solids was encountered. A further well was sunk closer to the town but water of unsuitable quality (1400 $\mathrm{mg} \mathrm{l}^{-1}$ t.d.s.) was found.

It was proposed to conduct a detailed resistivity survey to delineate the areal extent of the zone of saline groundwater and to determine whether this could be due to a westward incursion of saline groundwater from the coast. Thirty three Wenner resistivity soundings were conducted across the area, each normally achieving a maximum spacing of $128 \mathrm{~m}$. Example resistivity curves are shown in Fig. 3 together with their $C(s)$ parameter curves. Twenty one of the $C(s)$ curves each included more than $20 \%$ of points which were outside the range $0.75<C(s)<1.25$. Most of this irregularity was thought to be caused by near surface lateral resistivity variations.

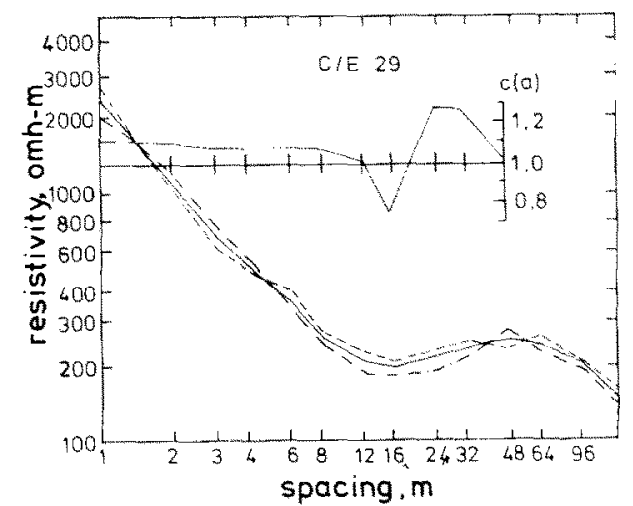

(a)

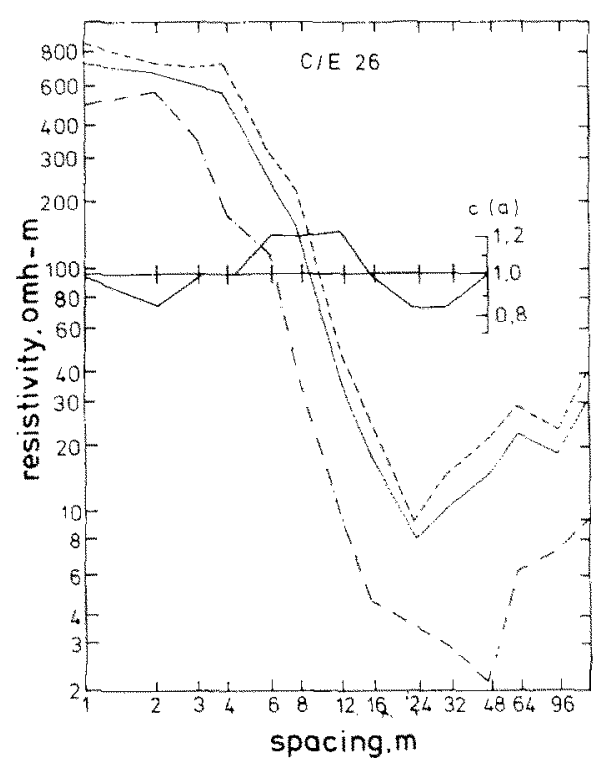

(b)

Fig. 3. Example resistivity curves from Canavieiras, Brazil: (a) good curves showing minimal effect of lateral resistivity variations; (b) sounding showing strong influence of lateral resistivity variations.

Interpretations were normally made in terms of four or five-layer models in which the deepest layer had an infinitely high resistivity. A frequency diagram of the resistivitics (Fig. 4) shows the clcar distinction between the electrical properties of these layers.

Electrical soundings were conducted adjacent to four of the boreholes, thus allowing a direct comparison of the geological and electrical sections (Fig. 5). In this example all sounding curves produced a five-layer interpreta- 


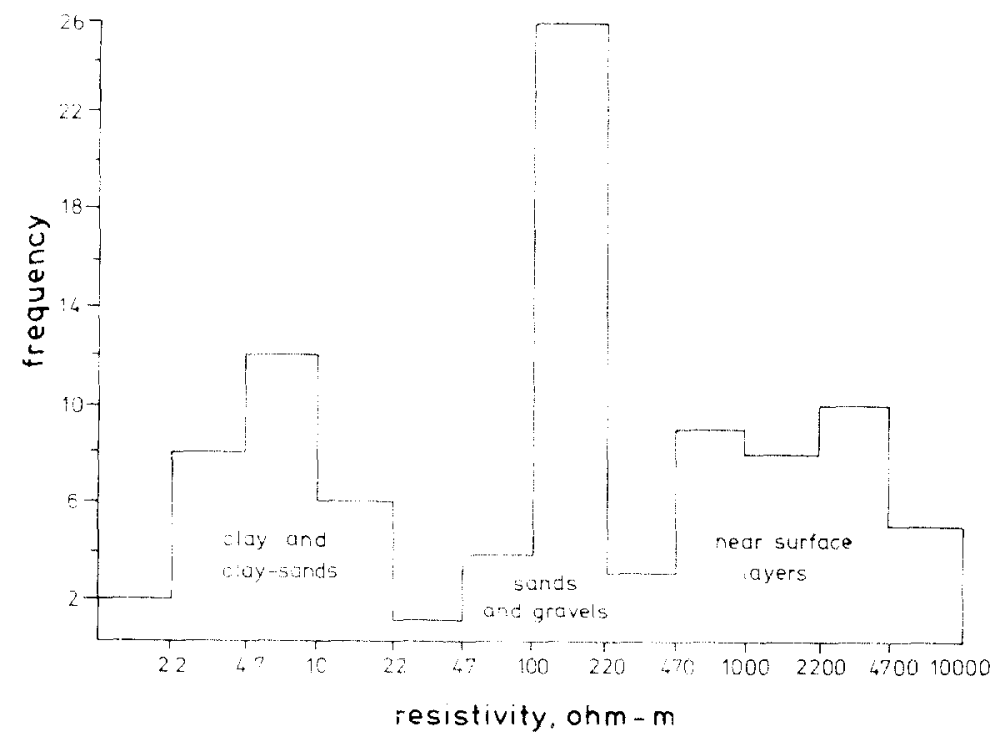

Fig. 4. Distribution of layer resistivities (excluding deepest high resistivity layer) indicating distinct characteristics of the three layers.

tion. The two near-surface layers probably represent a combination of the soil and weathered zone. The water table was not clearly defined but occurred within this thickness. The third and fourth layers are more clearly correlated with the sand and sandy clays shown in the lithological logs, the boundary between these two layers being accurately determined from the re. sistivity soundings.

The water supply for Canavieiras is drawn from the highly permeable near surface sands. These are shown to have a resistivity of between 100 and 150 $\Omega \mathrm{m}$ (Fig. 2). Their thickness varies irregularly from $10 \mathrm{~m}$ to $25 \mathrm{~m}$ across the area. The sands are underlain by sandy clays of much lower resistivity $(1-15$ $\Omega \mathrm{m})$ and of greater thickness $(40-60 \mathrm{~m})$.

The presence of high salinity groundwater saturating the sands in the region of well $P 1$ (Fig. 2) is confirmed. This appears to be of limited horizontal extent and shows no sign of having direct subsurface connections with the sea. However, an indirect connection through surface salt marsh is possible. It was found that surface marshland precluded the realization of electrical soundings between the Rio Pardo and well $P 1$. The extent of the marshlands was determined from aerial photographs and is shown in Fig. 2. It is possible that downward percolation of brackish water from the marshes has resuited in local pollution of the aquifer in this region.

The Tertiary sandstones of the Barreiras Formation underlie the recent sands and clays and exhibit much higher resistivities $(>100 \Omega \mathrm{m})$ than the overlying deposits. They are thought to be an alternative source of groundwater. However, in the region of $P 1$ the resistivity of this formation drops to less than $50 \Omega \mathrm{m}$ suggesting that the mineralized groundwater encountered in $P 1$ is fairly extensive in the vertical section. 


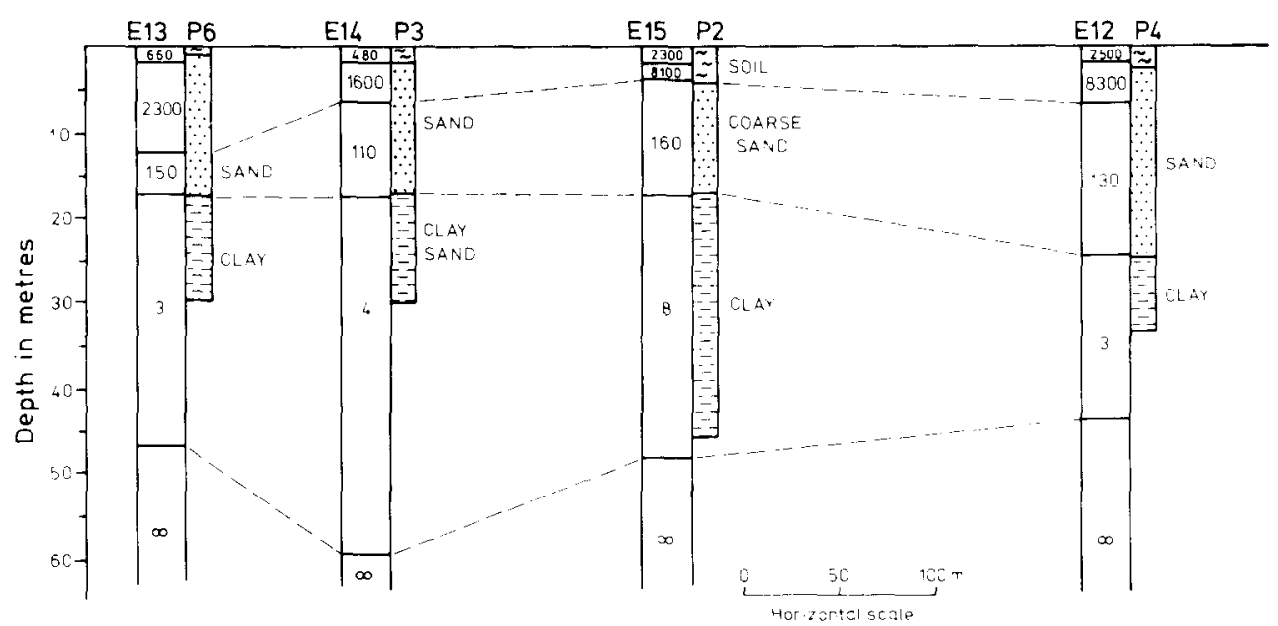

Fig. 5. Lithological section through wells $P 6, P 3, P 2$ and $P 4$ compared with interpretation of adjacent electrical soundings.

\section{CONCLUSIONS}

The use of the tripotential technique with the Wenner configuration has permitted the realization of high quality resistivity surveys under very difficult conditions and has assisted in solving several groundwater problems in the state of Bahia, Brazil. Our experience suggests that the method employed here will produce more accurate and more useful results than would be obtained with the Schlumberger configuration, an electrode arrangement which is also popularly employed where dry surface sands predominate.

\section{ACKNOWLEDGEMENTS}

The authors wish to thank Professor D.H. Griffiths for a useful criticism of the manuscript. One of the authors (J.L. Leite) wishes to express her thanks to the Conselho Nacional de Pesquisas, Brazil for a grant in aid of the research.

\section{REFERENCES}

Carpenter, E.W., 1955. Some notes concerning the Wenner configuration. Geophys. Prospect., 3: $388-402$.

Carpenter, E.W. and Habberjam, G.M., 1956. A tri-potential method of resistivity prospecting. Geophysics, 21: 455-469.

Ghosh, D.P., 1971. The application of linear filter theory to the direct interpretation of geoelectrical resistivity sounding measurements. Geophys. Prospect., 19: 192-217.

Leite, J.L., 1975. Estudo Geofísico dos Aquíferos costeiros nas Áreas de Canavieiras e Belmonte-Bahia. Unpublished M.Sc. Thesis. Programa de Pesquisa e Posgraduação em Geofísica, Universidade Federal da Bahia, Salvador, Brazil.

Wenner, F., 1912. The four-terminal conductor and the Thomson bridge. Bull. Bur. Stand. U.S., 8: $559-610$. 